\title{
Therapeutics
}

\section{Review: ziprasidone is as effective as haloperidol for schizophrenia but differs in adverse effects}

Bagnall AM, Lewis RA, Leitner ML, et al. Ziprasidone for schizophrenia and severe mental illness. Cochrane Review, latest version 27 Oct 1999. Oxford: Update Software.

QUESTION: In patients with schizophrenia or other related psychoses, what is the effectiveness of ziprasidone (a novel antipsychotic agent) compared with placebo, conventional, and other novel antipsychotic agents?

\section{Data sources}

Studies were identified by searching 10 databases and data services, reviewing the reference lists of relevant trials, contacting authors for additional studies, and contacting the manufacturer of ziprasidone for unpublished trials.

\section{Study selection}

Studies were selected if they were randomised controlled trials that included patients with schizophrenia or other related disorders and compared ziprasidone (oral or intramuscular) with placebo or other antipsychotic agents.

\section{Data extraction}

Data were extracted on patient characteristics and follow up, setting, interventions, outcome measures (clinical response, leaving the study early, and side effects), and methodological quality.

\section{Main results}

Analysis was by intention to treat. 7 trials were included (1564 patients). Trials lasted 1 week to $>6$ months. 3 trials were placebo controlled ( 2 could be combined $[\mathrm{n}=441])$ and 4 used haloperidol as the comparison group $(\mathrm{n}=829)$; no studies comparing ziprasidone with other novel antipsychotics were included. Ziprasidone was superior to placebo for several global effect and mental state measures (table). The groups did not differ for leaving the study early (overall $>40 \%$ ) or for side effects. For the ziprasidone and haloperidol comparison, no studies reported data on global effects. 1 study $(\mathrm{n}=132)$ reported change in Brief Psychiatric Rating Scale scores in favour of ziprasidone (3 days intramuscular, then 4 days oral) but another $(\mathrm{n}=301)$ showed no clear difference (4 weeks oral). The groups did not differ for leaving the study early (approximately 25\%). 2 studies lasting 1 week $(n=306)$ and 28 weeks $(n=301)$ found that ziprasidone, compared with haloperidol, was associated with less akathisia ( $\mathrm{NNT}=8,95 \%$ CI 5 to 18 and $\mathrm{NNT}=9$, CI 5 to 21 , respectively) and acute dystonia ( $\mathrm{NNT}=16$, CI 9 to 166), but caused more nausea and vomiting $(\mathrm{NNH}=5$, CI 4 to 5 and $\mathrm{NNH}=9$, CI 5 to 33 , respectively). 1 study $(n=301)$ reported similar mild weight gains for ziprasidone and haloperidol groups ( 0.8 to $0.9 \mathrm{~kg}$ in women and $0.3 \mathrm{~kg}$ in men).

\section{Conclusions}

In patients with schizophrenia or other related psychoses, ziprasidone is superior to placebo in measures of global effect and mental state. Movement disorders are less likely with ziprasidone than with haloperidol but ziprasidone causes more nausea and vomiting.
Source of funding.

National Health

Service Research \&

Development Health

Technology Assessment

Programme, UK.

For correspondence: Dr A M Bagnall, NHS Centre for Reviews and Dissemination, University of York, North Yorkshire YO10 5DD, UK. Fax $+44(0) 1904433661$.

Ziprasidone v placebo for schizophrenia at 4 to 6 weeks (2 studies)*

\begin{tabular}{|c|c|c|c|c|}
\hline \multirow[b]{2}{*}{ Outcomes } & \multicolumn{2}{|c|}{ Weighted event rates } & \multirow[b]{2}{*}{$\mathrm{RBI}(95 \% \mathrm{CI})$} & \multirow[b]{2}{*}{ NNT (CI) } \\
\hline & Ziprasidone & Placebo & & \\
\hline Global effect (CGI-I score >2) & $91 \%$ & $79 \%$ & $15 \%(10$ to 20$)$ & 9 (6 to 26$)$ \\
\hline $\begin{array}{l}\text { Mental state }(30 \% \text { decrease } \\
\text { in BPRS or PANSS) }\end{array}$ & $93 \%$ & $80 \%$ & $16 \%(6$ to 25$)$ & 8 (5 to 28$)$ \\
\hline
\end{tabular}

${ }^{*}$ CGI-I=Clinical Global Impression - Improvement; BPRS=Brief Psychiatric Rating Scale; PANSS=Positive and Negative Syndrome Scale. Other abbreviations defined in glossary; RBI, NNT, and Cl calculated from data in article.

\section{COMMENTARY}

Although it awaits marketing, there is already substantial interest in the novel antipsychotic ziprasidone. Pharmacologically it is truly novel. Like other atypical agents, it produces greater blockade of serotonin than dopamine receptors post-synaptically, but unlike its comparators it is also a moderate noradrenaline and serotonin reuptake antagonist and directly affects serotonin autoreceptors. ${ }^{1}$ These actions suggest a unique clinical profile. However, as shown in this review by Bagnall et al, the premarketing controlled trials do not endorse this prediction.

The reason for this discordance does not reflect the quality of the systematic review. The authors made great efforts to locate and analyse the available data without bias. It is simply the lack of informative data and the diversity of the study designs found that prevent a more useful evaluation of ziprasidone and limit the confidence clinicians may have when deciding how this agent might be used in their practice.

As with other novel agents, the reduction of extrapyramidal symptoms observed in this review is an important advantage that may predict less tardive dyskinesia. However, although a fair dose of oral haloperidol (flexible dosing $5-15 \mathrm{mg} / \mathrm{d}$ ) was used in the 6 month maintenance trial, it was excessive $(15 \mathrm{mg} / \mathrm{d})$ in the 4 week short term comparison. The finding of more nausea and vomiting is interesting and may reflect its serotonin reuptake activity. Does this action predict benefit in depressed patients or liability in bipolar patients? The most intriguing aspects of ziprasidone are its low propensity for EPS and its absence of weight gain with long term use $(\leqslant 1 \mathrm{y}){ }^{2}$ a combined feature not observed with other novel agents.

Reflecting its premarketing state of development, more questions than answers remain. Clinicians are left not knowing the effects of ziprasidone in patients with first episode psychosis and treatment refractory patients or its effect on affective, negative, and cognitive symptoms compared with contemporary alternatives. Policy decision makers will be similarly left wanting for comparisons addressing quality of life and healthcare resource use.

The challenge remains for ziprasidone to show that its clinical benefits emulate its pharmacological uniqueness.

David M Gardner, PharmD Dalhousie University Halifax, Nova Scotia, Canada

1 Tandon R, Harrigan E, Zorn SH. Ziprasidone: a novel antipsychotic with unique pharmacology and therapeutic potential. Journal of Serotonin Research 1997;4:159-77.

2 Arato M, O'Connor R, Bradbury JE, et al. Ziprasidone in the long-term treatment of negative symptoms and preventions of exacerbation of schizophrenia. In: XXIst Collegium Internationale Neuro-Psychopharmacologicum Congress (CINP). Glasgow, Scotland, 1998. 